\title{
GOING GREEN? THE IMPACTS OF SUSTAINABILITY PLANNING IN GREENSBURG, KANSAS, USA
}

\author{
L. HEWITT SPARKS ${ }^{1} \&$ S. SWEARINGEN WHITE ${ }^{2}$ \\ ${ }^{1}$ City of Bakersfield, Bakersfield, California, USA. \\ ${ }^{2}$ Urban Planning Department, University of Kansas, Lawrence, Kansas, USA.
}

\begin{abstract}
The small city of Greensburg, Kansas gained international attention through its efforts to rebuild sustainably following a devastating tornado in 2007. This study investigates the early results of those efforts, asking how both the built and social environments of Greensburg have changed as the result of sustainability-focused planning. Analysis of documents, observations, and interviews reveals that Greensburg's plans have had important influences on the city's built and social environments. Specifically, the materials, designs, and placement of buildings are substantially different than prior to the tornado, and reflect the city's sustainability emphasis. The greening efforts also appear to have enhanced citizen views of sustainability, with learning, costs, and community concerns as the main mitigating factors.
\end{abstract}

Keywords: community planning, disaster recovery, small cities, sustainability.

\section{INTRODUCTION}

On May 4, 2007, a tornado destroyed over $90 \%$ of the small city of Greensburg, Kansas. While that storm was noteworthy for its intensity and the scope of its devastation, it was Greenburg's disaster response that garnered international attention. As a city experiencing population decline and economic instability, Greensburg faced difficult odds with respect to its future viability well before the 2007 tornado. Yet, the community rallied together and developed a plan to rebuild a 'green' Greensburg, with a focus on sustainability principles.

Five years after Greensburg's tornado, it is possible to explore the early results of its sustainability efforts. This article draws from literatures on plan evaluation and implementation, behavior and the built environment, and sustainability planning, as well as data from documents and interviews with Greensburg residents and local officials, to consider to what extent both physical and social environments have changed since 2007 and how the sustainability-focused recovery process has influenced those changes. The sections that follow provide: a brief background for Greensburg and the 2007 tornado, a review of the relevant literature, and the case study methods, findings, and conclusions.

\section{GREENSBURG: BEFORE AND AFTER}

Greensburg is located in south central Kansas, approximately two hours west of Wichita, the state's largest city. Though it is the county seat of Kiowa County, Greensburg is very small. Only about 1,400 residents lived there prior to the 2007 tornado [1], representing a nearly 30\% drop in population over the previous four decades. As well, this part of the state of Kansas is aging, with almost one-quarter of the County's population aged 65 or over [1]. Greensburg was thus experiencing the same trends of decline common to many small, rural communities throughout the United States.

Despite these challenges, Greensburg maintained its civic pride. The City is home to two tourist attractions, the world's largest hand-dug well and world's largest pallasite meteorite, which drew numerous visitors each year. Pride in these and other community features have helped bolster Greensburg's resolve to rebuild over the last five years [2].

On the night of May 4, 2007, a tornado roughly a mile and a half (2.4 kilometers) wide and with winds in excess of 200 miles (320 kilometers) per hour swept through Greensburg. Virtually none of 
the town remained standing, and significant community structures including city hall, the hospital, and the local school were destroyed. Eleven people died, a figure that would undoubtedly have been much higher if the National Weather Service had not issued ample warning of the impending storm.

Given the extent of the tornado's destruction, early reports from the media suggested that Greensburg might well find it impossible to rebuild. But, within a few days after the disaster, it became clear that the question was how the city would recover, rather than if it would happen. The Kansas Governor, Kathleen Sebelius, quickly recommended that Greensburg use sustainability as an organizing principle in its rebuilding efforts. Simultaneously, others in the community, including the mayor at the time and the city manager, expressed similar ideas, noting that a different approach, such as that embodied in the notion of sustainable development, was needed to get the city back on its feet. For a small city in rural Kansas to tout sustainability principles may seem unlikely. One recent study [2] found that the key factors explaining Greensburg's approach to include: the shared vision and commitment of community leaders, the notion of sustainability as an opportunity, community pride and resilience, and a 'clean slate' for rebuilding that could take advantage of substantial funding sources for disaster recovery. The idea of a 'green' Greensburg thus took hold and informed the ensuing planning processes.

Two plans provide the foundation for this sustainability focus. With the assistance of the U.S. Federal Emergency Management Agency and input from hundreds of Greensburg residents who attended community visioning meetings, the City had the 'Long-Term Community Recovery Plan for Greensburg and Kiowa County' in hand just three months after the tornado. The second plan developed was the 'Greensburg Sustainable Comprehensive Plan', completed in May 2008 through a private consulting firm, again with extensive participation from residents. Both the recovery and comprehensive plans for Greensburg promote sustainability as a theme to inform every aspect of the community's rebuilding and future activities.

Over the past five years, considerable media attention has focused on Greensburg's rebuilding efforts, including hundreds of state and national newspaper articles, a special episode of National Public Radio, and a reality television program titled, simply, 'Greensburg'. Most recently, the fiveyear anniversary of the disaster has prompted the question of where Greensburg stands today, the effects of its recovery process, and how that process might inform similar efforts elsewhere. Assessing Greensburg's progress requires an understanding of plan implementation and evaluation and how the built environment influences attitudes and behaviors. While other cities grappling with disaster recoveries may not choose to rebuild with sustainability as a guiding principle, they will undoubtedly be interested in learning more of how that focus has influenced Greensburg's recovery. Communities of all types can also benefit from learning of the impacts of sustainability-focused planning on the built and social environments of a community.

\section{PLANS, THEIR IMPLEMENTATION, AND SUSTAINABILITY}

The literatures on plan evaluation and implementation, behavior and the built environment, and sustainability planning provide a useful basis for examining the early results of the sustainability-oriented tornado recovery in Greensburg. Much of the literature summarized here has a U.S. focus, not because it is the only or most important analysis of these issues, but because communities in the United States have tended to embrace different types of planning efforts with respect to sustainability than have other parts of the world [3].

Plans, of course, are a planner's primary tool for shaping communities [4]. As such, they provide a foundation from which these communities can work towards sustainability. Understanding the effectiveness of plans, however, and the ways and extent to which they bring about measurable outcomes, are areas of limited consensus. While the quality of a plan is a common area of investigation, one may 
evaluate a plan's quality at different stages, and with respect to different notions of what metrics are most important [5]. As well, there are two divergent approaches for evaluating a plan's implementation. The conformance approach focuses on outcomes, and examines the extent to which actual development reflects plan contents. The performance approach, in contrast, recognizes the need for plans to be adapted to ever-changing community circumstances and instead focuses on plan processes [6].

Recent studies of plan implementation and effects on the built environment have found generally low degrees of correlation between the specifics of plans and ensuing development [6-9]. One such study [9] identified plan quality, developer capacity and commitment, planning staff and agency capacity and commitment, and agency and developer interactions as key factors in implementation conformance. Another study [10], though, found that implementation success was higher in cases with greater stakeholder involvement in the planning process.

In addition to impacts on the built environment, plans conceivably alter the social environment of communities, in that they can influence the attitudes and behaviors of the people who reside there. Behavioral theory [11] suggests that the built environment shapes how people think and act within it through physical placement of structures and through explicit or implicit prompts such as sidewalks, recycling facilities, and so on. The types of attitudes and behaviors that can be influenced by physical surroundings clearly depend on the specifics of those surroundings, and thus on the plans that shape those specifics. Moreover, they depend on the social experience people have within their environments.

Jane Jacobs and Kevin Lynch [12-14] were among the first to recognize that the details of the built or physical environment alter community life through such aspects as travel behavior, sense of place, and access. In particular, connections between the built environment and travel behavior have emerged as a fertile area of research. Several studies [15-18] suggest that levels of pedestrian travel are higher in built environments that support walking through such amenities as pedestrian-friendly streetscapes, parks, and commercial activity. While the most important determinant of whether residents will walk to their destinations is likely distance [18-20], plans can be significant in that they make walking and biking relatively easier or more difficult through their influences on the built environment. Although there is little research that links plans with other aspects of behavior and the built environment, some [e.g., 21] have suggested that new urbanist or neo-traditional planning may prompt communities and their citizens to exist along the aspects of Lynch's theory of good city form. For example, communities that pursue notions of 'place identity' are more likely to make life more 'vivid and meaningful' for their residents [Ibid., p. 255]. It is not difficult to envision similar studies and results with respect to social behaviors such as recycling, energy conservation, and so on. The built environment undoubtedly influences our sustainability-related behaviors.

Studies of plans with a sustainability focus in the United States are still in a somewhat preliminary phase. Other parts of the world, particularly Europe, have a more comprehensive set of case examples, given the influence on community planning efforts of Local Agenda 21, the United Nations' action plan for sustainable development. U.S. communities and the United States as a whole, however, have not embraced Local Agenda 21 principles or other such international initiatives, and are instead pursuing a constellation of policy approaches loosely labeled as 'smart growth' [3]. U.S.focused studies are thus most appropriate for placing the Greensburg example in context, but it is important to note that this literature is somewhat limited. It has not yet, for example, addressed the question of the impacts of those plans on either built or social environments. Instead, these studies [e.g., 22-26] have mainly investigated the extent to which sustainability appears in city plans and policies. As well, these U.S.-focused studies have not examined planning efforts in very small cities such as Greensburg, given that such communities 'are thought to lack the resources to initiate a sufficient planning effort that considers sustainability concepts' [21]. Studies that do include smaller U.S. communities [22, 25] do not look at cities below a population of 2000 residents. 
Results of research on U.S. communities and sustainability planning to date suggest varying degrees of familiarity with and adoption of sustainability principles through the planning process. More specifically, sustainability does appear to have become a noticeable aspect of local government policies and techniques, at least in cities of greater than 50,000 residents [20]. However, very few cities have adopted a specific sustainability plan or otherwise integrated their various sustainability efforts [26]. Instead, these efforts are included within comprehensive land use plans [22] or through a variety of standard municipal policies [25]. Most efforts also focus on the ecological aspects of sustainability, as opposed to its economic and equity aspects [26].

While these lines of research suggest that plans and sustainability initiatives have the potential to bring about significant changes in communities, further questions remain. In particular, the impacts of sustainability-focused policies and plans have not yet received specific scrutiny in a U.S. context. Studies of sustainability performance emerging from Local Agenda 21 provide some guidance as to what U.S. communities might expect. For example, analyses of efforts in Germany and the Netherlands suggest that larger municipalities have better sustainability performance [27, 28]. Yet, specific impacts with respect to both built and social environments of a community are not well-understood. Moreover, the details of very small cities' approaches to sustainability planning are a further understudied area, since such cities tend to be examined only in combination with substantially larger communities.

The case of Greensburg, Kansas, then, provides an important lens through which to examine these issues. Based on its size alone, one might expect Greensburg to have struggled with its sustainability efforts $[27,28]$. Further studies of plan implementation suggest that plan quality, planner and developer capacity and commitment, and citizen participation in the planning process could be key influences on the degree of implementation success $[9,10]$. Of course, Greensburg's unique circumstances as a community recovering from a devastating natural disaster further complicate any hypotheses or conjecture concerning its progress to date [2]. The question guiding this study is: How has the sustainability-focused recovery process and comprehensive plan influenced Greensburg's built and social environments? This sort of general, impacts-focused inquiry is valuable to help develop a better understanding of the the results of community sustainability planning, particularly in a very small U.S. city such as Greensburg.

\section{STUDY APPROACH}

This project was conducted as a single, qualitative case study [29]. A case study 'demonstrate[s] a causal argument about how general social forces take shape and produce results in specific settings' [30]. In the case of Greensburg, these forces include the changes to that City brought about by the tornado and the ensuing planning processes. The focus is on the plan effects, since other work [2] has examined likely reasons for Greensburg's sustainability focus. While case study research may be limited with respect to its contributions to a theory of plan implementation [9], it remains a useful way to understand the complex dynamics of innovative plan settings.

Documents, observations, and interviews provided the data from which the research question could be answered. Documents analyzed included the 1982 Greensburg, Kansas Comprehensive Plan and the 2008 Greensburg Sustainable Comprehensive Plan [31, 32]. Observation data was gathered during two visits to Greensburg in September and November 2010. Interview data includes the results of a total of 16 semi-structured interviews with 18 individuals conducted in November 2010. Four interviewees were public officials: a planner, and the mayor, schools superintendent, and city administrator. The remaining 12 interviews were with Greensburg residents selected both randomly and strategically. Four interviews were determined randomly from a list of names that appears in a local report on recovery and resident relocation. Name recommendations from city officials yielded 
six interviews with individuals who both supported and opposed the City's sustainable redevelopment strategy. The final two interviews were conducted spontaneously with individuals encountered while visiting Greensburg. The interview sample was deemed to be sufficient when responses indicated redundancy. Thirteen interviews were recorded and transcribed; the interviewer took thorough notes on the remaining three.

Findings from the literature described above shaped the data analysis. Both the documents and interview transcripts and notes were examined and coded according to topics of interest. In the planning documents, these topics included visions, goals and objectives, and public participation processes. Understanding how the 1982 and 2008 plans differed with respect to these aspects helps evaluate both the plans themselves and their implementation. Within the interview data, coded themes related to the predominant perceptions of and attitudes toward the sustainability-focused recovery process and progress in Greenburg's recovery to date, including interviewee responses to that process and the ensuing changes in the community. The observation data primarily related to the design, structure, and materials of the built environment, drawing also on pre-tornado photographs as points of comparison. These observation data also provide a way to consider the extent to which the 1982 and 2008 comprehensive plans were/are being utilized in Greensburg. In all cases, the focus of the analysis was on changes to Greensburg's built and social environments that have occurred after the 2007 tornado. Identifying common patterns among these data sources allows data triangulation, which enhances the strength of study findings [33].

\section{FINDINGS AND DISCUSSION}

Understanding the influences of Greensburg's post-tornado plans is complicated by the fact that the recovery is not yet complete. Moreover, the recent global economic downturn has affected the City in ways this study is unable to measure. These are both study limitations. Nevertheless, the data analysis reveals that Greensburg's plans have brought about changes to both its built and social environments. The sections below address these aspects separately with respect to the three main data sources, and a concluding section considers the relationship between them. Interview data are labeled as $\mathrm{R}$ or $\mathrm{O}$ depending on whether the quotation is from a resident or local official. $\mathrm{R} 3$, for instance, indicates a quote from the third resident interview.

\subsection{Built environment}

The 2007 tornado obviously caused drastic changes in Greensburg's built environment. Simply by necessity, the City now has new buildings of all types, from residential, to commercial, to institutional. The ways that these buildings and their environs follow or depart from previous city conditions, however, is arguably a function of the 2008 Sustainable Comprehensive Plan, which has guided the land use elements of the tornado recovery process. Comparing the 1982 plan to the 2008 plan, and images and interviewee recollections of the pre- and post-tornado settings, demonstrates the types of changes that have occurred.

A systematic evaluation and comparison of the 1982 and 2008 comprehensive plans was not possible. Initially, city officials indicated that the only copies of the 1982 plan were lost in the tornado. While eventually a single copy of that plan was located [31], officials did not permit it to be removed from City Hall or photocopied in its entirety. Thus, the analysis here is based on the introductory section of the 1982 plan, its Land Use chapter, and the appendix that described the public participation process. In addition, the plans are at two different stages with respect to their potential evaluation [5]. While one would expect the 1982 plan to be fully implemented by 2007 , full implementation of the 2008 plan will not occur for several more years. The feasible points of comparison between the 
two plans, then, include their vision, goals and policies, and the public participation process that informed them. Evidence of their utilization is found in the details of the built environment both before and after the 2007 tornado and through interviewee reflections.

With respect to the two plans' visions for Greensburg, each seeks to foster a balanced, thriving community, with slightly different emphases. Specifically, the 1982 plan envisioned Greensburg would:

work toward the achievement of a balanced community of public, residential, commercial and industrial land uses while recognizing the efficiency offered by jointly providing certain facilities and services in cooperation with Kiowa County; and to strive to be a healthy, safe, convenient and efficient community with a pleasant and attractive atmosphere for shopping, working, leisure time and everyday living [25].

The 2008 plan's vision is twofold. First, its so-called 'Common Vision' is simply: 'A Sustainable Future'. Its 'Community Vision' describes the City as 'blessed with a unique opportunity to create a strong sense of community devoted to family, fostering business, working together for future generations' [32]. This new plan, then, has a broader emphasis in its vision, plus one which promotes sustainability as an overarching theme as well as an opportunity.

Goals, objectives, and policies in the 1982 plan are very general. They include goals such as, 'Minimize the amount of through traffic in residential districts which increases accidents, reduces property values, and lessens the amenities of residential areas', and policies such as, 'vacant areas within the city should be developed first' [31]. These items do not indicate their linkages to community conditions at the time. In contrast, goals, objectives, and policies in the 2008 plan are directly connected to the Greenburg's post-tornado situation and are much more specific. For example, policies include the following: 'Building design shall incorporate day-lighting strategies for occupied areas to reduce reliance on electrical lighting and to strengthen a connection to the outdoors' [32]. This policy reflects the community's sustainability-related interests in rebuilding in such a way as to promote both energy conservation and more natural conditions within the buildings themselves. Another 2008 policy states: 'Stormwater best management practices (BMPs) and native plantings should be integrated into the landscaping to provide an amenity that also displays Greensburg's sustainable vision' [Ibid., p. 53]. Again, evidence of Greensburg's commitment to sustainability is explicitly reflected here.

The public participation process reflected within the two plans is also substantially different. Citizen involvement in the 1982 plan appears to have been limited to a survey about city conditions sent to 200 randomly selected residents. In contrast, the 2008 plan describes how it was developed through extensive input from Greensburg residents, including but not limited to four community meetings to discuss planning issues and review plan drafts; each of these meetings drew 300-400 people [32]. This number is all the more remarkable when considering that only about 700 people were living in Greensburg at that time. The interview data corroborate the assertion that the 2008 plan included substantially more public participation. While two of the interviewees still suggested that they did not feel they were involved in the planning process, a more common sentiment is reflected in the words of a resident interviewee who said: 'I really felt we did as good a job as we possibly could as a community getting input from everyone about what they wanted to see in Greensburg; that was probably one of the single most important things we did... and a key part of the planning' (R3).

Finally, a comparison of the utilization of the two plans suggests that prior to the tornado, comprehensive plans were not a priority for the City of Greensburg. As noted above, city officials first thought that no copy of the 1982 plan had survived the storm and were unsure of the date of that 
plan. Also, none of the residents interviewed were aware of the prior plan's existence. In addition, the 1982 plan was designed to last through the year 2000. No updates to it had ever occurred, nor did it appear to be used in any type of discussions about the city's growth and development. This planning void, combined with the 'blank slate' conditions in Greensburg following the tornado, allowed the 2008 plan to emerge as a document of necessity in guiding the city's rebuilding efforts. In contemplating the use of the new document, the city planner assisting Greensburg with its recovery observed that the plan is being followed 'far better than any other community I have ever worked at. I have been a planner for 30-something years and for maybe five different communities. The city is following the plan much more closely than any other place I've been. We actually refer to it on a regular basis' (O3). Other city official interviewees indicated that the 2008 plan will continue to be shaped and made more specific as conditions in the community change. It is thus viewed as what two officials described as 'a living document' (O1; O3).

The ways that the current built environment of Greensburg differs from the previous built environment reflect the differences between the two plans, though obviously many changes were a direct function of the tornado. For example, given that the vast majority of Greensburg's pre-tornado housing stock dated from before 1930 or the 1950s, newer housing styles and materials are an inevitable effect of the disaster. On the other hand, the plan and its sustainability emphasis seem to have influenced the choice of building materials, landscaping materials, and building placement.

Interview data indicate that Greensburg residents and city officials alike recognize the benefits of rebuilding the city with respect to energy efficiency and improved building technology. As one mentioned, prior to 2007, Greensburg 'was falling down around us, decaying, you know, around downtown... The buildings were highly inefficient and we were just dying inch by inch' (R11). Seven of the twelve residents interviewed chose to use one or more green building practices for the reconstruction of their homes, including geothermal heating and cooling systems, solar panels, water collection systems, and high-efficiency appliances and insulation. These green building practices are even more apparent with regard to Greensburg's municipal buildings. Ahead of but in concert with the green building emphasis in the 2008 plan, in December 2007 the City Council resolved that all city-owned buildings larger than 4,000 square feet would be built to 'platinum' standards, the highest standards available under the U.S. Green Building Council's Leadership in Energy and Environmental Design (LEED) program. As a result of these initiatives, the Greensburg City Hall, Kiowa County School, Kiowa County Memorial Hospital, and the Kiowa County Commons building were all built to LEED platinum standards [34]. Figures $1-4$ below show the differences between the pre- and post-tornado school and hospital. Other LEED platinum buildings include the 5.4.7. Arts Center,

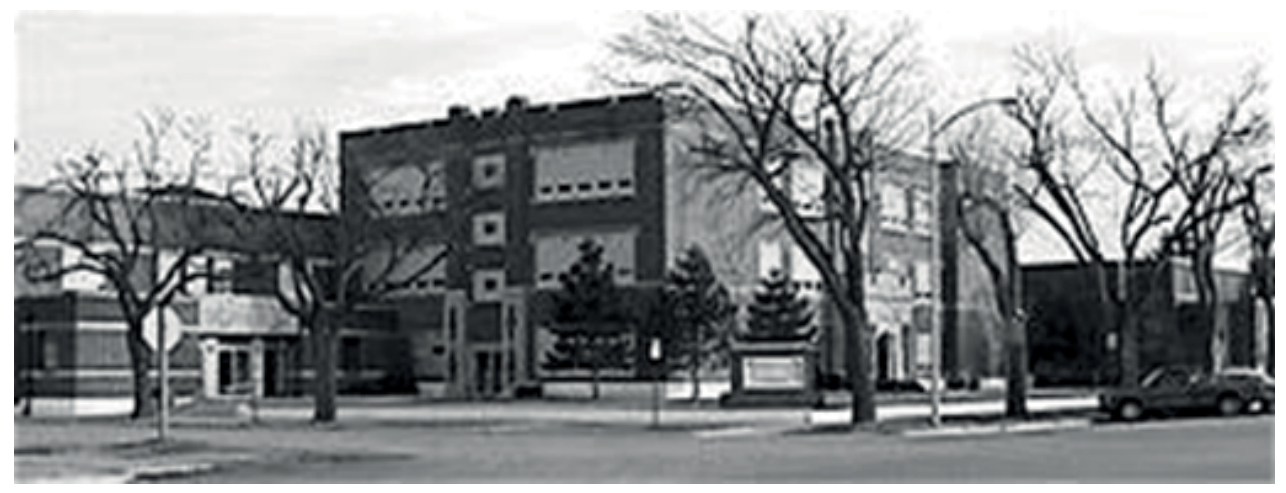

Figure 1: Pre-tornado School (photographer unknown). 


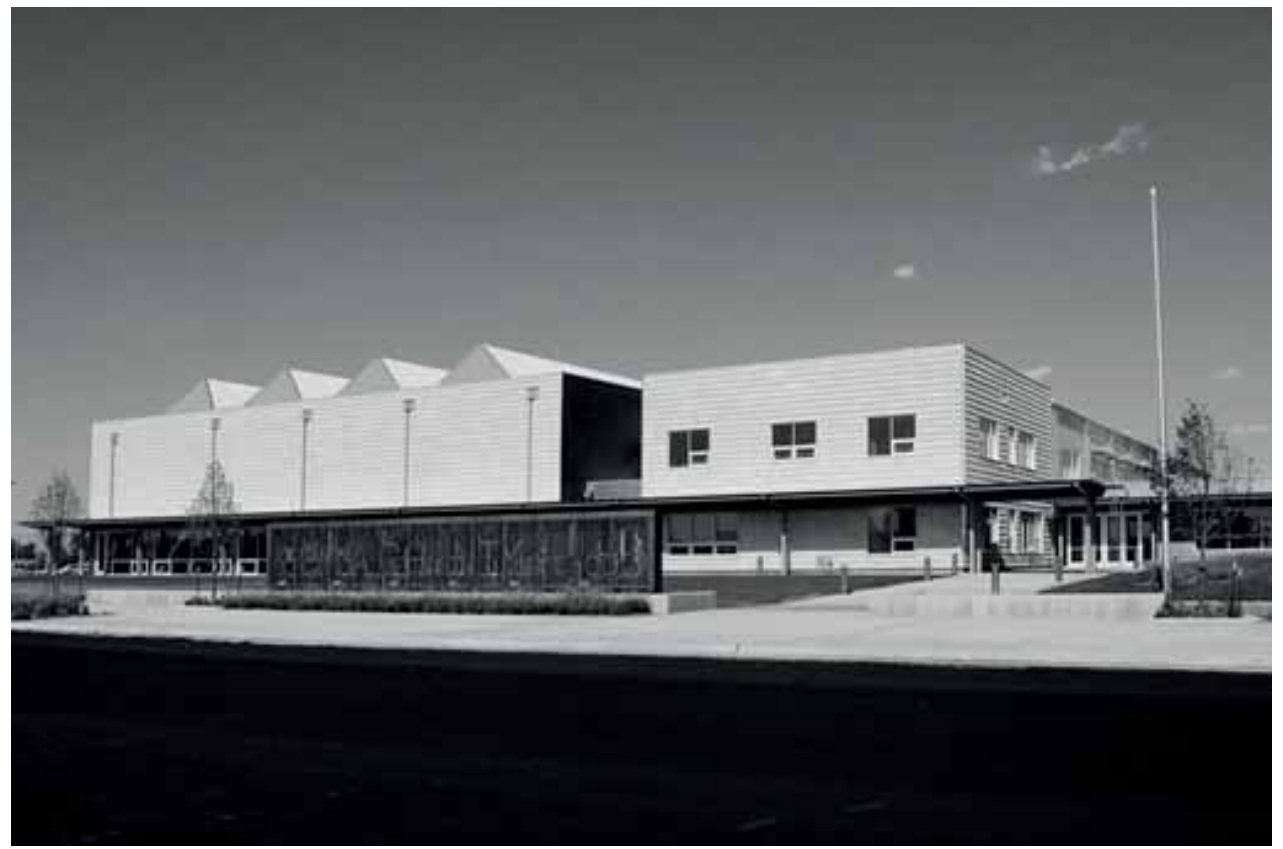

Figure 2: Post-tornado School (photo by Joah Bussert).

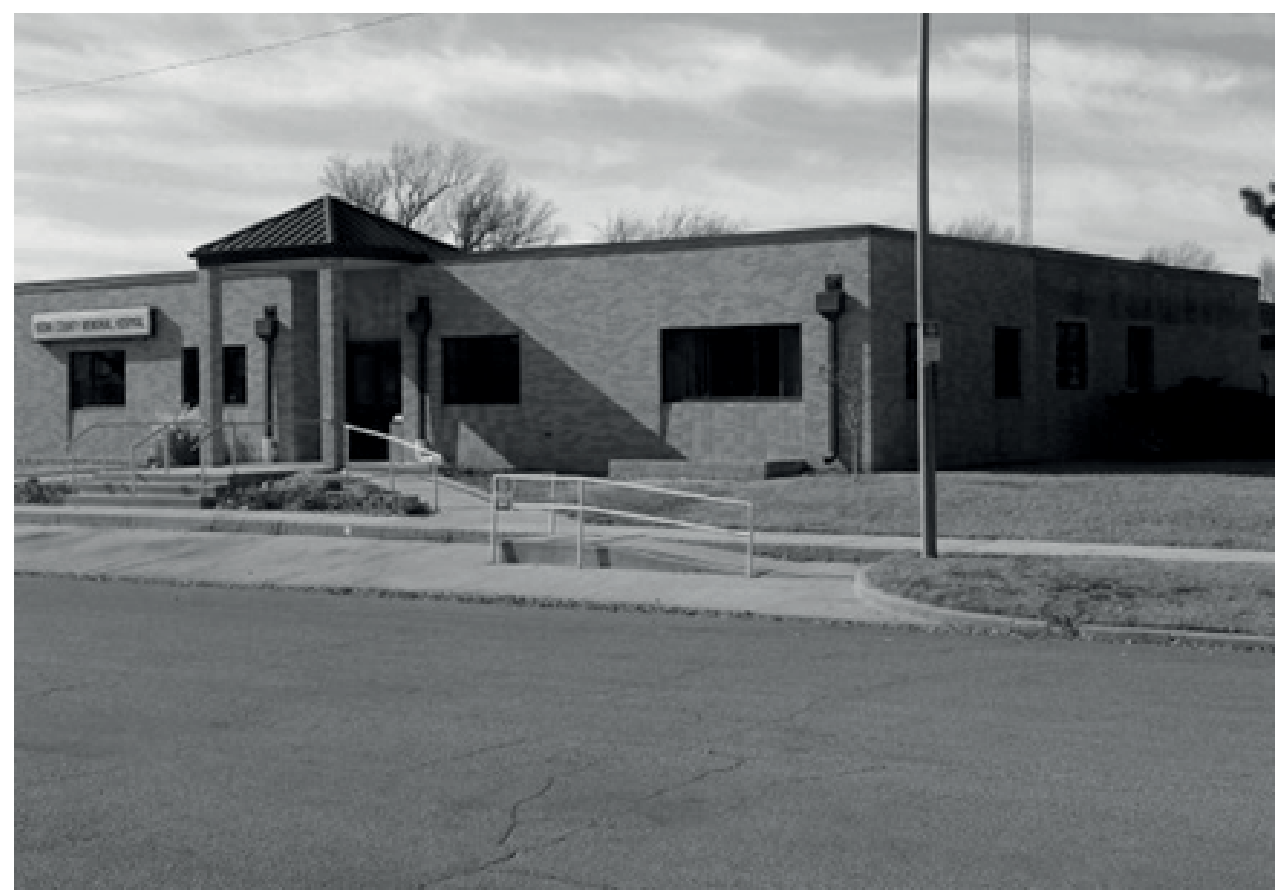

Figure 3: Pre-tornado Hospital (photo by Mary Sweet). 


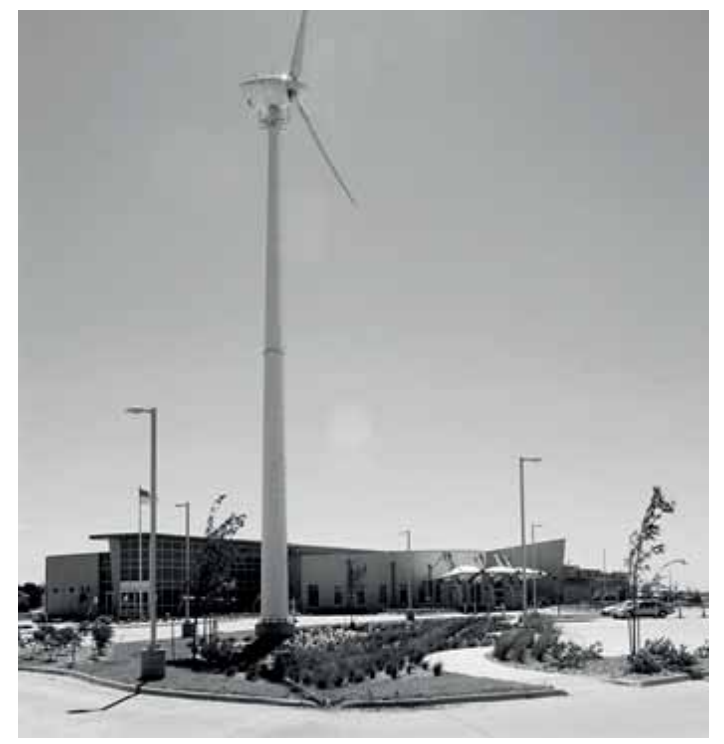

Figure 4: Post-tornado Hospital (photo by Joah Bussert).

designed and built by architecture students at the University of Kansas, and the Sun Chips Business Incubator. Private buildings built to LEED standards include Centera Bank, the John Deere Dealership, and the Prairie Point Town House Complex [34].

Beyond the materials of its new buildings, Greensburg's post-tornado built environment reflects other aspects of its efforts to promote sustainability. For example, the City's Main Street now has energy-efficient LED lighting, which saves an estimated 70 percent in energy and maintenance costs, and reduces light pollution due to the lights' downward focus. Solar panels and wind turbines are visible in and from downtown, and providing further evidence that Greensburg has embarked on a different path as a community. In addition, the City partnered with John Deere Wind Energy and recently completed the Greensburg Wind Farm, LLC. Located three miles south of town, and connected to the Kansas Power Pool, Greensburg's grid connection, this 10-turbine wind farm produces enough power for 4000 homes [34].

The City's landscaping is also substantially changed. The 2007 tornado destroyed nearly all of Greensburg's trees, leaving little shade and an open view of the entire town. In the interviews, a common theme for residents was the change to the City's appearance. After the tornado, it seemed bigger, more open, and brown. Sustainability appears to have influenced the replanting efforts, though. As one resident put it: 'Before the tornado, I would have gone down to the nursery and bought any old plants and put them in there. But instead, I got zero water plants to put in and I am trying not to water more than once a week for just a short time. And before the tornado, I would have never given it a thought' (R11). As well, the City has utilized best management practices for its stormwater runoff, relying on native plants and bioretention areas along Main Street, and incorporating green roofs on its new City Hall and Commons buildings. Figures 5 and 6 illustrate the changed appearance of some of these elements of the City.

Lastly, Greensburg has altered the placement of its buildings and roadways to reflect its sustainability emphasis. Shortly after the tornado, residents argued over whether buildings should be rebuilt in the same locations or relocated. Ultimately, the community decided that some changes were 


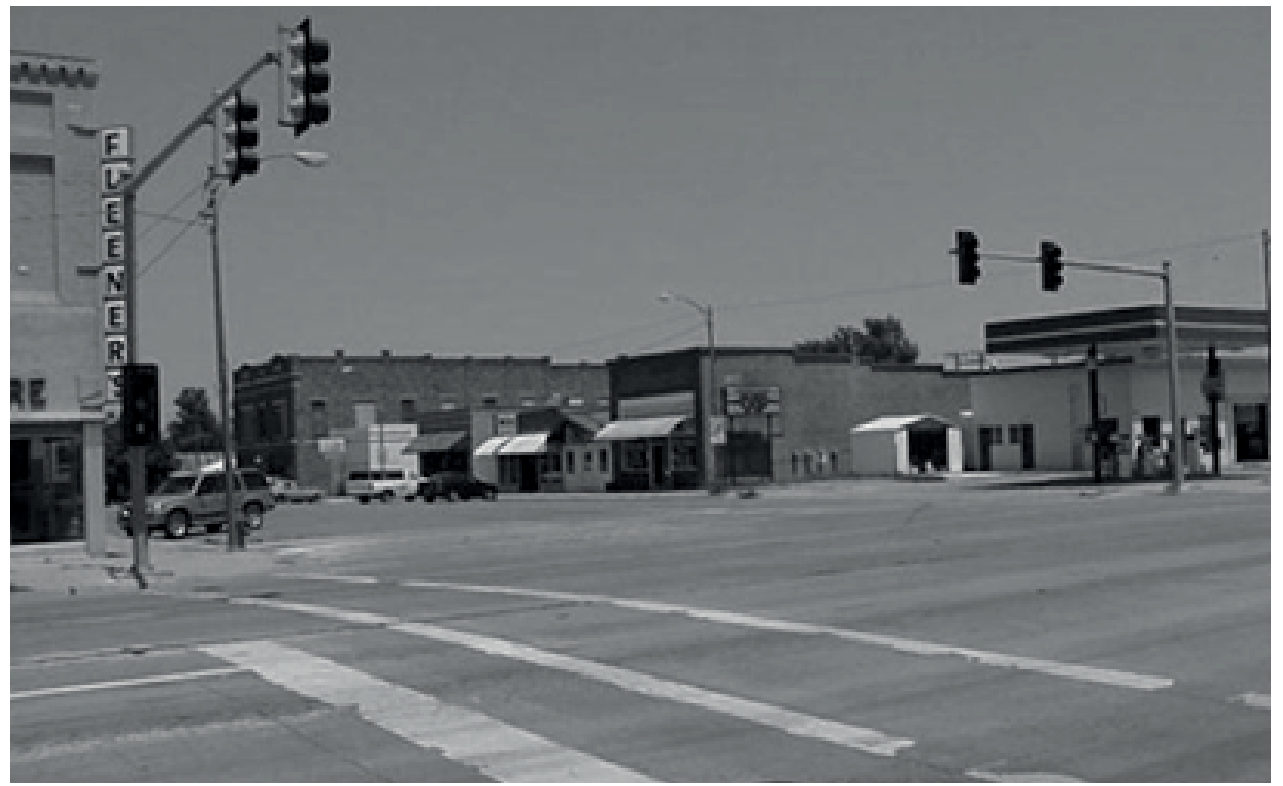

Figure 5: Pre-tornado Main Street (photo by Warren Smith).

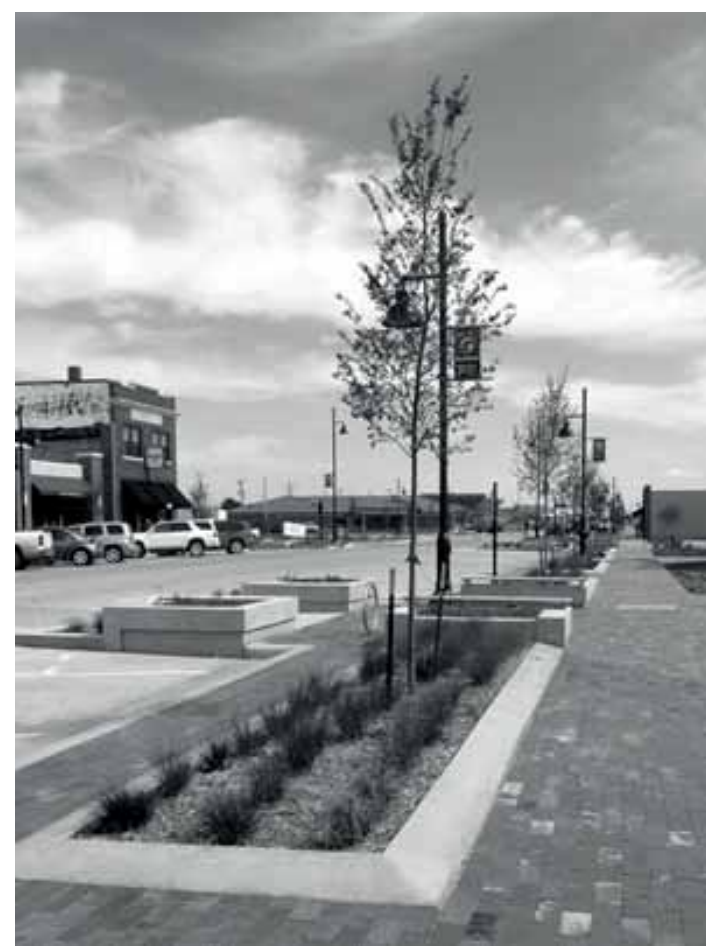

Figure 6: Post-tornado Main Street (photo by Stephanie Peterson). 
needed to actualize the City's vision, and to leave a legacy for future generations. In particular, the library, school, hospital, and the highway were relocated. The hospital, for example (see Figs 3 and 4), had previously been located in the center of town, and was moved to the edge of the City in an effort to reduce land use conflicts. As one local official observed:

If you look around town, a lot of things are in different locations than they were before the tornado. And that's because they are in better locations. For example, the hospital used to be in the middle of town. So, any time an ambulance made a run, it went right by residential houses and right through neighborhoods to get to places, and that was not always safe. ... So a lot of things have been reorganized... Fortunately, we took a little more time and planned a little better and because of it, I think in the end we will have a better, more sustainable product $\left(\mathrm{O}_{2}\right)$.

In addition, the City has set aside space to accommodate more parks and walking and biking paths. For instance, as funds become available, a space between the new Big Well Museum (which opened in May 2012) and the new City Hall will be developed into a park to accommodate community events such as the farmers' market.

Although Greensburg's built environment will continue to develop and change in years to come, the City's early recovery clearly reflects the sustainability path upon which the City has embarked. Its comprehensive plan uses sustainability as a focal point, and the development of that plan engaged citizens in ways previous planning efforts had not. Interviews and observations further reflect a widespread, if somewhat subtle, change to the ways the City looks and functions.

\subsection{Social environment}

In addition to changes in Greensburg's built environment, the sustainability-oriented planning and rebuilding process also seems to have fostered changes in the City's social environment, broadly understood as the way people think about and act within their community. Data from the interviews and observations reveal that this process has influenced the attitudes and behaviors of Greensburg residents. While interview data provide accounts of attitudes and behaviors, rather than the actual behaviors themselves, themes that emerged in the interviews do indicate the areas of greatest influence with respect to residents' perceptions.

In general, interviewees demonstrated interest in and backing of Greensburg's sustainability initiatives. Nine of the twelve residents interviewed agreed with and supported the City's sustainability focus. The remaining three, however, disagreed with this focus. Interestingly, these three individuals still reported an increased awareness of sustainability principles and one even indicated having made significant sustainability-related changes in her everyday life. Yet when speaking of the sustainability initiatives, these residents complained, that 'the city is forcing us to fit in this mold', and that ideas had been 'shoved down our throats' (R12). It would thus appear that sustainability awareness and some behavioral change has resulted from Greensburg's efforts even if individuals have concerns about sustainability as a recovery focus.

The three interrelated themes that emerged as most prominent in interviewees' thoughts about Greensburg's sustainability initiative were learning, costs, and the sustainability of the community as $a$ whole. These themes appear to be the mitigating factors influencing residents' attitudes and behaviors with respect to sustainability. In some cases, they are the factors that have transformed these attitudes and behaviors in significant ways.

Learning, in a general sense, and reflected in numerous educational opportunities, is perhaps the most critical element of residents' shifts in sustainability-related attitudes and behaviors. Several 
interviewees reported a gradual transformation of their views of sustainability as they learned more about it. Initially, residents were skeptical of Greensburg's focus on sustainability, and feared it was reflective of a political agenda with which they disagreed. Over time, and as they learned more, their views changed. As one interviewed resident put it:

I think people were really hesitant because they always associated 'green' with being liberal. And I think they realize now that being green isn't all solar panels and wind generators and expensive stuff. It's the little things like what our ancestors used to do such as hanging clothes on the line and gardening without chemicals and reusing and recycling. They realized it really is just being good stewards of things, taking care of things. And it's not really political at all. It's not Republican or Democrat or liberal or conservative. It's just a good way to be (R2).

Another interviewee expressed a similar initial reluctance to embrace sustainability, and the eventual realization that 'I was just ignorant to the correlation to sustainability, the green movement, and the ecological and economic impact we have on this earth. ... And as I opened my mind up to be educated in a lot of different aspects, I realize the green movement is a very good thing' (R10).

Twelve of the sixteen interviewees noted specifically that learning played an important role in shaping attitudes towards and support for sustainability, for both them and other community members. This learning process was informal, in terms of the larger community conversations occurring around the rebuilding plans, and formal, with respect to workshops and other opportunities offered by the City, the newly formed non-profit group Greensburg GreenTown, and other organizations. Interviewees observed that these learning opportunities also extend to Greenburg's youth. The new school building, for example, is itself instructive, providing students with information on its various sustainable features, including energy and water efficiency and materials.

Learning in Greensburg also appears to be occurring through what social psychologists describe as the realm of social influence [11]. Residents watched their neighbors rebuild with sustainability in mind and in turn were influenced by what they saw. Four interviewees noted specifically that residents held each other accountable for their actions (O1; R6; R10; R11). They did not want their friends and neighbors to see them making less sustainable choices, and their attitudes and behaviors were influenced as a result. One resident described this process as follows:

The first [houses after the tornado] were built quickly and were not really energy efficient. We were really the first ones that started building a really energy efficient house. So I think it was an influence on other people. People would come over here and ask me what I'm doing and why I'm doing it that was and all this... But a lot of people, I think, learned a lot really quickly from the whole effort and seeing their neighbors do it (R6).

Learning, then, occurred in numerous ways after the tornado, and has influenced the residents of Greensburg in both their thinking and their behaviors with respect to sustainability.

A second theme from the interviews, and one that plays a comingled role with the theme of learning, is that of cost. Disaster recovery under any circumstances is tremendously expensive, and Greensburg's response to near-total destruction has emphasized new sustainability approaches which themselves are often perceived as costly. As a result, fourteen of the sixteen interviewees noted that costs were an important factor shaping their attitudes and behaviors with respect to the City's post-tornado efforts.

For a small number of these individuals, misperceptions linger. Three of the twelve resident interviewees expressed anger that Greensburg was spending millions of dollars of 'taxpayer' money on redeveloping the City with LEED buildings, when they believed the City's recovery, even an 
environmentally-conscious recovery, was possible at a much lower cost (R7; R8; R12). Interestingly, and perhaps not surprisingly, these were the same three interviewees who disagreed with the sustainability focus of the recovery. Local officials and five other residents, on the other hand, explained that it was relief funds and numerous private donations, not tax dollars, which made these projects possible. Moreover, despite higher upfront costs of green building, those costs become savings with respect to operations over time. Gaps clearly persist in the ways people in Greensburg perceive the costs of the sustainability-focused recovery, and these gaps are likely influencing individual and community attitudes.

Costs also influence the behaviors of Greensburg residents. Interviewees revealed that for many in the community, the insured value of their homes was much less than the costs of rebuilding it. Residents would thus incur significant out-of-pocket costs as they sought to rebuild. As a result, their desires to include more sustainable features in their homes were tempered by very practical concerns about what they could afford in the short-term. The fourteen interviewees who mentioned costs noted that they included green features in their new homes to the extent they could afford to do so. One interviewee captured this sentiment succinctly: 'You build as green as you can with the green that you got' (R3).

Just as the themes of learning and cost appear to be intertwined for Greensburg residents as they navigate their post-tornado lives, the third and last theme to emerge from the interview data suggests additional complexity in the ways that these individuals consider and act on sustainability. Indeed, the overall sustainability of Greensburg as a viable city is an overarching theme of influence for many in that community, across a spectrum of attitudes. Residents and local officials alike indicated that they are simultaneously worried and hopeful that the sustainability emphasis will allow Greensburg to thrive into the future.

As the City's population decline and lack of economic development were concerns long before the 2007 tornado, it is not surprising that residents still worry about these issues. In the minds of some residents, the sustainability emphasis has not achieved its promised results. Three of the twelve residents interviewed, again the same three with the previously negative views, indicated that the City has not seen the growth projected as a result of the green redevelopment process. One stated: 'They keep promising people, growth, and industry as a result of the green redevelopment. If it attracted people and brought the 'opportunity' they are talking about, I would think differently about this whole [sustainability initiative] but it hasn't' (R7).

As well, these less optimistic residents fear that the sustainability emphasis has actually deterred some individuals and businesses from locating in Greensburg. This concern is expressed by the resident who said that Greensburg:

...will never grow. You would have seen more population and the businesses would have been more willing to come back, but they didn't because the city kept telling them you have to build this green building... And that was their whole attitude. If you can't build green, we don't want you (R12).

Greensburg's current mayor shared a similar concern, noting more specifically that the City should have been clearer at the outset that building green is not mandatory. While this mayor was not in office at the time of the tornado, he has been supportive of and has continued to implement the sustainability initiatives.

Of course, many of the interviewees also recognize that the global economic downturn has played a large role in the slow pace of Greensburg's recovery. Seven interviewees mentioned this specifically. Within this recognition lies a more hopeful set of views concerning the sustainability path on which the City has embarked. A common belief among interviewees is that despite the challenges, 
Greensburg's sustainability emphasis was the community's best possible choice. A local official described his views of what the City was facing before the tornado:

It [was] just a typical rural community. And rural communities are dying. So, if we rebuilt the community the same way it was, we were destined for the same future, which wasn't real positive. So we started looking at if you're coming down 54 Highway, why stop here? ... What can we do that sets us apart from anywhere else? What would make you more likely to live here than some other town along the highway? We had to have something different to offer $\left(\mathrm{O}_{2}\right)$.

The sustainability emphasis became that 'something different'.

For those who believe that the emphasis on sustainability will help secure a solid future for Greensburg, signs of success are apparent. One such sign is the presence of younger families moving to the community. This included two of the interviewees, who grew up in Greensburg, moved away, and then returned after the tornado specifically because of the sustainability initiative there. Another resident remarked on this change by saying: 'We used to be one person to a house and now I bet we're averaging three or four to a house, just because our population is younger. We never had that before. We never had that kind of growth' (R11). These residents maintain a hopeful attitude that Greensburg's sustainability efforts will continue to encourage younger people to move there to raise families.

In addition, those people who see the City's sustainability efforts as essential to its future believe that tourism will play a prominent role. While the town's two main attractions, the world's largest hand-dug well, and world's largest pallasite meteorite, drew many tourists annually before the 2007 disaster, residents observe that since that time, the sustainability efforts have played an even bigger part in bringing people to Greensburg. Describing this phenomenon, a resident commented:

If Greensburg had not decided to go green... it would be like every other town that has had a disaster. After about six months or so, everybody has forgotten about them. This effort is going to keep people coming to town to look at this. There are some people that hate what the [new LEED buildings] look like. But those buildings and the way they were built are bringing people here to see them (R6).

These residents have come to believe that tourism will be a vital part of Greensburg's future economy, and that the greening efforts are a cornerstone of that future.

\section{CONCLUSIONS}

Independent of its sustainability-oriented planning process, the 2007 Greensburg tornado inevitably brought immense change to that rural Kansas community. Despite its unique circumstances, it is apparent from this research that the details of the City's plans for both its recovery period and beyond have influenced its built and social environments in numerous ways. Without a sustainability emphasis, new construction might have been more energy efficient, but it would almost certainly not have involved the adoption of LEED building standards and other green features that are so evident today in public and private structures alike. Analysis of the two comprehensive plans, interviews and observations all point to substantial differences in the materials and functions of Greensburg's built environment, changes that reflect the emphasis on sustainability. As the recovery process continues, and assuming the comprehensive plan is still followed, these changes are likely to continue to be noteworthy aspects of the community.

Greensburg's social environment has also changed. While the dynamics are complex, it appears that learning, costs, and the community's future have all been influential aspects of the ways that people there think about and act with respect to its sustainability focus. On the whole, the effects are 
primarily positive. Residents express a deeper understanding of sustainability and its benefits. In some cases, these residents changed their views of sustainability from a liberal political agenda focused only on the environment to a common-sense approach consistent with their values. The choices they have made in their rebuilt homes, their choice of landscaping, and so on reflect those views, which also seem to encompass an understanding of sustainability that reflects environmental, economic, and equity concerns.

With respect to the more general lessons of this study and its contribution to the literatures on plan evaluation and implementation, behavior and the built environment, and sustainability planning, several preliminary conclusions are possible. It would appear, for instance, that small cities do have the capacity to be innovative and successful with respect to sustainability, provided the local commitment is present. Further, plans can shape attitudes and behaviors through broad impacts on the built and social environments. A city like Greensburg that embraces sustainability as a guiding principle of its comprehensive plan is thus likely to see impacts beyond travel behaviors (where previous studies have focused). The conclusion of a prior study [10] that plan implementation success is linked to greater stakeholder involvement in the planning process also seems to be validated here. The fact that hundreds of residents, over half of the remaining population, took part in this process in Greensburg suggests that they learned about sustainability issues and other elements of the plan that might otherwise have escaped their notice. Still, planners should take note that even extensive public participation does not eliminate the perceptions of small numbers of residents that the planning process excluded their viewpoints.

Greensburg residents are observing dramatic changes to their physical and social surroundings as the community rebuilds and plans for its future. The process of watching and interacting with neighbors seems to be important to these residents' understanding of and support for sustainability. In this sense, planners should be attuned to the social dynamics that plans can engender, and should look for opportunities to enhance plan implementation through these interactions.

Of course, concerns remain. Because the tornado recovery period coincides with a global economic recession, it is not surprising that some people in Greensburg are skeptical of the long-term effects of the sustainability efforts on their community. Yet, while it is impossible to know what conditions in Greensburg would be today had the City pursued a different type of recovery, or, more vividly, if they tornado had not occurred, it is reasonable to expect that adverse recession impacts would still be very visible.

As planners continue to contemplate plan implementation and effectiveness, the case of Greensburg, Kansas shows that it is important to consider both physical and social impacts of plans. Ultimately it is the people who live in a place who will experience the effects of plans, and those experiences can be shaped by plan quality and the overall planning process. Greenburg's small size and post-disaster planning imperative may make it an unusual case, but these lessons are worthy of further investigation in many contexts.

\section{REFERENCES}

[1] Institute for Policy and Social Research, 2010, Kansas Statistical Abstract 2009, $44^{\text {th }}$ Edition. available at http://www.ipsr.ku.edu/ksdata/ksah/KSA44.pdf

[2] White, S.S., Out of the rubble and towards a sustainable future: the 'greening' of Greensburg, Kansas. Sustainability, 2(7), pp. 2302-2319, 2010. doi: http://dx.doi.org/10.3390/su2072302

[3] Krueger, R. \& Gibbs, D., 'Third wave' sustainability? Smart growth and regional development in the USA. Regional Studies, 42(9), pp. 1263-1274, 2008. doi: http://dx.doi.org/10.1080/ $\underline{00343400801968403}$ 
[4] Dalton, L., The limits of regulation: evidence from local plan implementation in California. Journal of the American Planning Association, 55(2), pp. 151-168, 1989. doi: http://dx.doi.org/ $10.1080 / 01944368908976015$

[5] Baer, W., General plan evaluation criteria: an approach to making better plans. Journal of the American Planning Association, 63(3), pp. 329-344, 1997. doi: http://dx.doi.org/10.1080/ $\underline{01944369708975926}$

[6] Laurian, L., Day, M., Berke, P., Ericksen, N., Backhurst, M., Crawford, J. \& Dixon, J., Evaluating plan implementation: a conformance-based methodology. Journal of the American Planning Association, 70(4), pp. 471-480, 2004. doi: http://dx.doi.org/10.1080/01944360408976395

[7] Berke, P., Backhurst, M., Day, M., Ericksen, N., Laurian, L., Crawford, J. \& Dixon, J., What makes plan implementation successful? An evaluation of local plans and implementation practices in New Zealand. Environment and Planning B: Planning and Design, 33(4), pp. 581-600, 2006. doi: http://dx.doi.org/10.1068/b31166

[8] Brody, S. \& Highfield, W., Does planning work? Testing the implementation of local environmental planning in Florida. Journal of the American Planning Association, 71(20), pp. 159-175, 2005. doi: http://dx.doi.org/10.1080/01944360508976690

[9] Laurian L., Day, M., Backhurst, M., Berke, P., Ericksen, N., Crawford, J., Dixon, J. \& Chapman, S., What drives plan implementation? Plans, planning agencies, and developers. Journal of Environmental Planning and Management, 47(4), pp. 555-577, 2004. doi: http:// dx.doi.org/10.1080/0964056042000243230

[10] Burby, R., Making plans that matter: citizen involvement and government action. Journal of the American Planning Association, 69(1), pp. 33-49, 2003. doi: http://dx.doi.org/10.1080/ $\underline{01944360308976292}$

[11] Winter D., \& Koger, S., The psychology of environmental problems, 2nd edn., Lawrence Erlbaum Associates: Mahwah, NJ, 2004.

[12] Jacobs, J., The death and life of great American cities, Vintage Books: New York, 1961.

[13] Lynch, K. \& Rodwin, L., A theory of urban form. Journal of the American Institute of Planners, 24(4), pp. 201-214.

[14] Lynch, K., A theory of good city form, MIT Press: Cambridge, MA, 1981.

[15] Plas, J. \& Lewis, S., Environmental factors and sense of community in a planned town. American Journal of Psychology, 24(1), pp. 109-143, 1996.

[16] Kitamura, R., Mokhtarian, P. \& Lander, L., Micro-analysis of land use and travel in five neighborhoods in the San Francisco Bay area. Transportation, 24(2), pp. 125-158, 1997. doi: http:// dx.doi.org/10.1023/A:1017959825565

[17] Lund, H., Testing the claims of new urbanism: local access, pedestrian travel, and neighboring behaviors. Journal of American Planning Association, 69(4), pp. 414-429, 2003. doi: http:// dx.doi.org/10.1080/01944360308976328

[18] Greenwald, M. \& Boarnet, M., Built environment as determinant of walking behavior: analyzing non-work pedestrian travel in PDX, OR. 80th Annual Meeting of the Transportation Research Board, paper 01-2792, 2001.

[19] Handy, S., Urban form and pedestrian choices: a study of Austin neighborhoods. Transportation Research Record, 1552: pp. 135-144, 1996 doi: http://dx.doi.org/10.3141/1552-19

[20] Shriver K., Influence of environmental design in pedestrian travel behavior in four Austin neighborhoods. Transportation Research Record, 1578: pp. 64-78, 1996. doi: http://dx.doi.org/ 10.3141/1578-09

[21] Ford, L.R., Lynch revisited: new urbanism and theories of good city form. Cities, 16(4), pp. 247-257. doi: http://dx.doi.org/10.1016/S0264-2751(99)00023-2 
[22] Berke, P. \& Conroy, M.M., Are we planning for sustainable development? An evaluation of 30 comprehensive plans. Journal of American Planning Association, 66(1), pp. 21-33, 2000. doi: http://dx.doi.org/10.1080/01944360008976081

[23] Portney, K.E., Taking sustainable cities seriously: Economic Development, the Environment, and Quality of Life in American Cities, MIT Press: Cambridge, MA, 2003.

[24] Jepson, E.J., The adoption of sustainable development policies and techniques in US cities: how wide, how deep, and what role for planners? Journal of Planning Education and Research, 23(2), pp. 229-241, 2004. doi: http://dx.doi.org/10.1177/0739456X03258638

[25] Conroy, M.M., Moving the middle ahead: challenges and opportunities of sustainability in Indiana, Kentucky, and Ohio. Journal of Planning Education and Research, 26(1), pp. 18-27, 2006. doi: http://dx.doi.org/10.1177/0739456X06289664

[26] Saha, D. \& Paterson, R.G., Local government efforts to promote the 'three Es' of sustainable development: survey in medium to large cities in the United States. Journal of Planning Education and Research, 28(1), pp. 21-37, 2008. doi: http://dx.doi.org/10.1177/0739456X08321803

[27] Kern, K., Koll, C. \& Schophaus, M., Local agenda 21 in Germany: an inter- and intranational comparison. Berlin social science research center, discussion paper, 2004.

[28] Hoppe, T. \& Coenen, F., Creating an analytical framework for local sustainability performance: a Dutch case study. Local Environment, 16(3), pp. 229-250, 2011. doi: http://dx.doi.org/10.10 $\underline{\text { 80/13549839.2011.565466 }}$

[29] Yin, R., Case Study Research: Design Methods, 2nd edn., Sage Publications: Thousand Oaks, CA, 1994.

[30] Walton, J., Making the theoretical case. What is a case? Exploring the Foundations of Social Inquiry, eds. C.C. Ragin \& H.S. Becker, Cambridge Press: New York, pp. 121-137, 1992.

[31] Indian Hills Association of Local Governments, Greensburg, Kansas Comprehensive Plan, (Retrieved from Greensburg, Kansas City Hall 11/10), 1982.

[32] Greensburg, K., 2008, Greensburg Sustainable Comprehensive Plan, available at http://www. greensburgks.org/recovery-planning/greensburg\%20comprehensive $\% 20$ master\%20plan\% 2001-16-08\%20Draft.pdf.

[33] Patton, M.Q., Qualitative Evaluation and Research Methods, 3rd edn., Sage Publications: Newbury Park, CA: 1990.

[34] Greensburg GreenTown, GreenTour Book, 1st edn., available at: http://www.greensburggreentown.org/tour-book/, 2010. 